УДК 373.1

DOI 10.23951/2307-6127-2020-1-195-199

\title{
ОБРАЗОВАТЕЛЬНЫЕ ВОЗМОЖНОСТИ РАЗНОВОЗРАСТНЫХ СООБЩЕСТВ УЧАЩИХСЯ НА СЕЛЕ
}

\author{
Р. М. Шерайзина, А. Г. Ширин, Л. В. Тайкова
}

Новгородский государственный университет имени Ярослава Мудрого, Великий Новгород

Предлагается анализ феномена разновозрастного обучения в сельской школе, представлены образовательные задачи, решаемые малокомплектными школами, раскрыто содержание понятий «условие», «педагогические условия». Рассмотрены условия организации образовательного процесса в сельской школе (процессуальные, содержательные, управленческие, психолого-педагогические, дидактические, методические, социокультурные). Охарактеризованы функции обучения детей разного возраста (психологические, социальные, компенсаторные, стимулирующие). Представлено определение разновозрастных групп учащихся на селе.

Ключевые слова: образовательные возможности, процесс обучения, разновозрастные сообщества, обучение на селе.

Сегодня сельская школа занимает одно из важных мест в осуществлении просвещения сельского населения, оказывая влияние и на жизнь села в целом.

Разновозрастные сообщества являются основой для организации процесса обучения, поскольку в него включены учащиеся, педагоги, родители, общественность села.

В педагогической науке в исследованиях, посвященных разновозрастным сообществам, акцент делается на «разновозрастном обучении» или «обучении в ходе межвозрастного взаимодействия» (Л. В. Байбородова, М. Батербиев) [1, 2], а также многоуровневом и мультивозрастном обучении, смешанно-возрастном $[1,2]$.

Проблема обучения разновозрастных сообществ учащихся и организации межвозрастного взаимодействия рассматривается в работах С. Л. Ильюшкиной, Е. И. Павловой, Е. Б. Штейнберга, С. Н. Сафроновой, С. П. Федоровой, Е. Н. Герасимовой, А. Ю. Кругликовой, А. А. Остапенко, В. Б. Лебединцева, А. Н. Ермаковой, Л. А. Крапивина и др. [3].

Следует отметить, что термин «сообщество» предполагает некую систему отношений между людьми, имеющими что-то общее.

Многими учеными отмечается, что в процессе объединения детей в разновозрастные группы увеличивается их мотивация при решении разного рода задач, возрастает эффективность урока, меняется система взаимоотношений между старшими и младшими учащимися, иначе воспринимается педагог, что способствует успешному достижению целей образования.

Вопросы, связанные с организацией процесса обучения в разновозрастных классах сельской школы, рассматривают в своих научных исследованиях Н. В. Байгулова, Т. К. Жилкалкина, В. И. Кузнецова, П. И. Ломакина, Н. А. Щетинина и др. [3].

В процессе развития ребенка и становления его как личности взаимодействие с окружающим миром и людьми остается главным фактором его успешной социализации. В зависимости от того как осуществляется данное взаимодействие, происходит усвоение ребенком нравственных и культурных ценностей, получение практического опыта. 
Так, находясь в школе, ребенок постоянно контактирует с педагогом и учащимися. Однако сегодня человек взаимодействует с людьми разного возраста. Примерами такого взаимодействия выступают семья, учебные группы, рабочий коллектив и др.

Б. М. Дощанова отмечает, что малокомплектные школы решают такие образовательные задачи, как:

- обеспечение потребности учащихся сельской школы в получении образования;

- уравнивание изначальных возможностей выпускников школы [4].

Вместе с тем, помимо обозначенных задач, сельская школа решает ряд специфических задач, а именно: сдерживает отток выпускников из сельской местности; помогает повышению культурного уровня населения; воспитывает человека, способного организовать прибыльное дело в условиях села, и др.

Роль разновозрастных групп и их влияние на процесс обучения и воспитания отмечал А. С. Макаренко, он рассматривает разновозрастные группы как необходимое условие развития полноценной личности ребенка [5].

Идею А. С. Макаренко о важности и рациональности создания разновозрастных сообществ учащихся - трудовые отряды, сельскохозяйственные кружки, художественные коллективы, ученические группы по месту жительства и др. - поддерживал и развивал В. А. Сухомлинский, при этом отмечая, что в школе функционируют разные коллективы и что первичный коллектив, т. е. класс сверстников, никак не может исчерпать всего богатства отношений ребят [6].

Л. Ю. Гордин отмечает преимущество создания разновозрастных групп в возможности организации соревнования учащихся [7].

Разновозрастное обучение предполагает организацию учебной деятельности детей разного возраста, способствующей реализации как общих для всех образовательных и воспитательных задач, так индивидуальных, возникающих в ходе образовательного процесса у учащихся.

Организация процесса обучения детей разного возраста предполагает осуществление ряда функций:

- психологической - расширение контактов, взаимное обогащение детей, возможность устранить психологическое напряжение учащихся и т. д.;

- социальной - помощь старших младшим в процессе учебной деятельности;

- компенсаторной - возможность для старших учащихся принять на себя роль взрослого, принять на себя ответственность;

- стимулирующей - способствовать проявлению у учащихся индивидуальных особенностей, которые в условиях класса остались бы незамеченными.

Так, мы можем говорить о том, что разновозрастное обучение на селе способствует успешному решению организационных вопросов и повышает обучающий потенциал учебной деятельности. Вместе с тем необходимо учитывать условия, в которых протекает разновозрастное обучение.

Философский энциклопедический словарь трактует термин «условие» как нечто, от чего зависит что-то другое [8].

В педагогической литературе термин «условие» рассматривается как обстоятельство, определяющее эффективность педагогической деятельности. В свою очередь педагогические условия представляют собой совокупность действий, ориентированных на повышение успешности педагогической деятельности и включающих в себя все компоненты процесса обучения, такие как цель, задачи, методы, приемы, формы работы. 
Педагогические условия представляют собой совокупность мер, способствующих увеличению эффективности педагогической деятельности.

Н. В. Ипполитова характеризует педагогические условия как компонент педагогической системы, отражающий внутренние (личностное развитие учащихся) и внешние (комплексное решение познавательных и общекультурных задач) элементы, обеспечивающие ее успешное функционирование и развитие [9].

В. Б. Лебединцев определяет несколько групп педагогических условий, которые необходимы для организации процесса обучения в разновозрастных группах в сельской школе: процессуальные условия - индивидуальный темп освоения учебного материала; освоение учебного материала; подвижный состав учебных групп; активное взаимодействие всех участников в процессе учебной деятельности и др.; содержательные условия - разнообразие обучающего материала и форм взаимодействия учащихся и т. д.; управленческие условия - разработка индивидуальных маршрутов; готовность педагогов к осуществлению разновозрастного обучения; рефлексия деятельности и др. [10].

Вместе с тем образовательный процесс в сельской школе предполагает реализацию таких педагогических задач, которые предусматривают специфику работы с малыми учебными группами; индивидуальные возможности учащихся; отбор наиболее эффективных методов и приемов работы для формирования у учащихся системы базовых знаний; построение педагогом индивидуального маршрута обучения учащихся; развитие умения учиться самостоятельно; формирование активной позиции учащегося по отношению к процессу обучения и общению с другими учащимися; успешное усвоение учебного материала в процессе взаимодействия учащихся; условия, определяемые особенностями сельской жизни.

Таким образом, обучение в школе представляет собой значимый период в жизни ребенка, поскольку в это время, помимо приобретения знаний, ребенок получает опыт взаимодействия со сверстниками, а также с разновозрастными группами. В процессе такого взаимодействия происходит усвоение жизненно важных навыков и умений, которые будут способствовать успешному становлению учащегося в дальнейшей жизни как профессионала и обеспечат его конкурентоспособность и востребованность в обществе.

Изучение различных научных источников доказывает, что правильно организованное обучение в разновозрастной группе способствует созданию прочного ученического коллектива, способствует воспитанию у учащихся ответственности, дисциплинированности, развитию инициативы, взаимопомощь.

Совместная деятельность учащихся, педагогов, родителей, селян является основой для всестороннего и гармоничного развития личности ребенка, его нравственных, патриотических, интеллектуальных качеств. Именно в процессе такой деятельности зарождается чувство ответственности за результаты своих действий, за происходящее вокруг в целом.

\section{Список литературы}

1. Байбородова Л. В. Взаимодействие в разновозрастных группах учащихся. Ярославль: Академия развития, 2007. $336 \mathrm{c.}$

2. Батербиев М. М. Разновозрастное обучение. От идеи до реализации. Братск: Издательский дом «Братск», 2001.142 с.

3. Батербиев М. М. Дидактические основы проектирования образовательного учреждения с разновозрастными учебными группами (VII-XI классы общеобразовательной школы): автореф. дис. ... канд. пед. наук. М., 2002. 25 с.

4. Дощанова Б. М. Разновозрастное обучение в малокомплектной школе // Современная высшая школа: инновационный аспект. 2012. № 1. С. 91-94.

5. Макаренко А. С. Коллектив и воспитание личности. М.: Педагогика, 1972. 334 с.

6. Сухомлинский В. А. Воспитание коллективизма у школьников. М.: Педагогика, 1956. 93 с.

7. Гордин Л. Ю. Коллективное самообслуживание школьников. М., 1965. 248 с. 
8. Философский энциклопедический словарь / гл. редакция: Л. Ф. Ильичёв, П. Н. Федосеев, С. М. Ковалёв, В. Г. Панов. М.: Сов. энциклопедия, 1983.840 с.

9. Ипполитова Н., Стерхова Н. Анализ понятия «педагогические условия»: сущность, классификация // General and Professional Education. 2012. № 1. C. 8-14.

10. Лебединцев В. Б. Коллективные учебные занятия как средство обеспечения индивидуальных учебных траекторий учащихся малочисленных сельских школ: дис. ... канд. пед. наук. Красноярск, 2008. 212 с.

Шерайзина Роза Моисеевна, доктор педагогических наук, профессор, Новгородский государственный университет имени Ярослава Мудрого (ул. Большая Санкт-Петербургская, 41, Великий Новгород, Россия, 173003). E-mail: Roza.Sherayzina@novsu.ru

Ширин Александр Глебович, доктор педагогических наук, доцент, Новгородский государственный университет имени Ярослава Мудрого (ул. Большая Санкт-Петербургская, 41, Великий Новгород, Россия, 173003). E-mail: Alexander.Shirin@novsu.ru

Тайкова Людмила Владимировна, магистрант, Новгородский государственный университет имени Ярослава Мудрого (ул. Большая Санкт-Петербургская, 41, Великий Новгород, Россия, 173003).E-mail: lg8987@mail.ru

Материал поступил в редакцию 04.12.2019.

DOI 10.23951/2307-6127-2020-1-195-199

\section{EDUCATIONAL OPPORTUNITIES OF DIFFERENT AGE COMMUNITIES OF STUDENTS IN RURAL AREAS}

\section{R. M. Sherayzina, A. G. Shirin, L. V. Taykova}

\section{Yaroslav-the-Wise Novgorod State University, Veliky Novgorod, Russian Federation}

In the article we offer an analysis of the phenomenon of heterogeneous education in a rural school, provide educational tasks that are solved by small schools, and reveal the contents of the concepts "condition" and "pedagogical conditions". We examined the conditions for organizing the educational process in a rural school (procedural; substantive; managerial; psychological and pedagogical; didactic; methodological; sociocultural). Characterized the learning functions of children of different ages (psychological, social; compensatory; stimulating). They provided a definition of students of different ages in rural areas. The educational process in a rural school involves the implementation of such pedagogical ones that involve the organization of educational activities in small educational groups; taking into account individual characteristics and inclinations of students; selection of training content, selection of methods, forms of work, ensuring the formation of students' knowledge, skills; construction by the teacher of an individual learning route for students; development of the ability to learn independently; successful assimilation of educational material in the process of student interaction; conditions determined by the characteristics of rural life. Properly organized training in a different age group contributes to the creation of a strong student team, helps to educate students in responsibility, discipline, and the development of initiative.

Keywords: educational opportunities, learning process, communities of different ages, rural education.

\section{References}

1. Bayborodova L. V. Vzaimodeystviye $v$ raznovozrastnykh gruppakh uchashchikhsya [Interaction in student groups of different ages]. Yaroslavl', Akademiya razvitiya Publ., 2007. 336 p. (in Russian). 
2. Baterbiyev M. M. Raznovozrastnoye obucheniye. Ot idei do realizatsii [Different age training. From idea to implementation]. Bratsk, Izdatel'skiy dom "Bratsk" Publ., 2001. 142 p. (in Russian).

3. Baterbiyev M. M. Didakticheskiye osnovy proyektirovaniya obrazovatel'nogo uchrezhdeniya s raznovozrastnymi uchebnymi gruppami (VII-XI klassy obshcheobrazovatel'noy shkoly). Avtoref. dis. kand. ped. nauk [Didactic principles of designing an educational institution with different age groups (VII-XI classes of a comprehensive school). Abstract of thesis cand. ped. sci.]. Moscow, 2002. 25 p. (in Russian).

4. Doshchanova B. M. Raznovozrastnoye obucheniye $v$ malokomplektnoy shkole [Different age education in a small school]. Sovremennaya vysshaya shkola: innovatsionnyy aspekt - Contemporary Higher Education: Innovative Aspects, 2012, no. 1, pp. 91-94 (in Russian).

5. Makarenko A. S. Kollektiv i vospitaniye lichnosti [Team and personality education]. Moscow, Pedagogika Publ., 1972. 334 p. (in Russian).

6. Sukhomlinskiy V. A. Vospitaniye kollektivizma u shkol'nikov [The education of collectivism in schoolchildren]. Moscow, Pedagogika Publ., 1956. 93 p. (in Russian).

7. Gordin L. Yu. Kollektivnoye samoobsluzhivaniye shkol'nikov [Collective self-service of schoolchildren]. Moscow, 1965. 248 p. (in Russian).

8. Filosofskiy entsiklopedicheskiy slovar'. GI. redaktsiya: L. F. Il'ichyov, P. N. Fedoseyev, S. M. Kovalyov, V. G. Panov [Philosophical Encyclopedic Dictionary]. Moscow, Sovetskaya entsiklopediya Publ., 1983. 840 p. (in Russian).

9. Ippolitova N., Sterhova N. Analiz ponyatiya "pedagogicheskiye usloviya': sushchnost', klassifikatsiya [Analysis of the concept of "pedagogical conditions": essence, classification]. General and Professional Education, 2012, no. 1, pp. 8-14 (in Russian).

10. Lebedintsev V. B. Kollektivnyye uchebnyye zanyatiya kak sredstvo obespecheniya individual'nykh uchebnykh trayektoriy uchashchikhsya malochislennykh sel'skikh shkol. Dis. kand. ped. nauk [Collective training sessions as a means of providing individual educational trajectories for students of small rural schools. Diss. cand. ped. sci.]. Krasnoyarsk, 2008. 212 p. (in Russian).

Sherayzina R. M., Yaroslav-the-Wise Novgorod State University (ul. Bolshaya Sankt-Peterburgskaya, 41, Veliky Novgorod, Russian Federation, 173003).

E-mail: Roza.Sherayzina@novsu.ru

Shirin A. G., Yaroslav-the-Wise Novgorod State University (ul. Bolshaya Sankt-Peterburgskaya, 41, Veliky Novgorod, Russian Federation, 173003).E-mail: Alexander.Shirin@novsu.ru

Taykova L. V., Yaroslav-the-Wise Novgorod State University (ul. Bolshaya Sankt-Peterburgskaya, 41, Veliky Novgorod, Russian Federation, 173003).E-mail: 1g8987@mail.ru 